\title{
Serial learning and filled and unfilled delay intervals: Effects of informative feedback contingencies*
}

\author{
SAM S. RAKOVER and MALKA MAON \\ University of Haifa, Haifa, Israel
}

The effects of filled and unfilled delay intervals both preceding and following informative feedback was studied in a serial learning experiment. Unfilled dalay as well as filled and unfilled postfeedback delay intervals were found to facilitate learning in comparison to immediate informative feedback. The effect of filled delay did not differ significantly from that of immediate informative feedback. The results are interpreted in terms of a short-term/long-term storage mechanism.

Experiments dealing with the effect of delay of informative feedback (IF) on human Ss' verbal learning have shown that it does not parallel the retardation effect of delay of reinforcement found in animal studies (Jones \& Bourne, 1964). Although Saltzman (1951) showed that IF delay retards verbal learning, later studies indicate that it has no such effect (Bourne \& Bunderson, 1963; Kintsch \& McCoy, 1964), and still others demonstrate a facilitative effect (Atkinson, 1969; Buchwald, 1967; Jones, 1968).

It has been shown that in comparison to filled IF delay, unfilled IF delay enhanced learning. The reasons suggested were that Ss can use this unfilled interval for rehearsal or for analysis of the verbal responses (Atkinson, 1969; Jones, 1968). Filled IF delay does not allow for these facilitative operations.

Another important variable is the post-IF delay: the time interval between IF and the next stimulus. Some studies have shown that unfilled post-IF delay is also an important facilitative factor (Bourne \& Bunderson, 1963; Jones, 1968; Jones \& Bourne, 1964). As an explanation of this phenomenon, it was suggested that Ss use this delay to process or rehearse the information they have obtained. These studies, however, did not examine the effect of filled post-IF delay interval on learning.

The aim of the present experiment was to study the effect of the location of the delay interval (preceding or following IF) and the type of delay interval (filled or unfilled) in a serial learning experiment. It was predicted that unfilled delays either preceding or following IF would facilitate learning, while filled delays would retard it.

\section{METHOD}

Subjects

Forty psychology students, 18 male and 22 female, volunteered to participate in the experiment. There were eight Ss per group, with average age and sex composition kept constant over the five groups.

*Sponsored by George E. Briggs, who takes full editorial responsibility for its contents.

\begin{abstract}
Design and Procedure
A list of eight Hebrew words was used; they were shown for $3 \mathrm{sec}$ each on a memory drum in a serial anticipation method. The words, taken from Balgur (1968), had a frequency rank of $5 / 20,000$.

In the usual serial anticipation method, a stimulus had the following functions: stimulus, response, IF, and cue to report the next stimulus. To create a post-IF delay, one has to separate the cue function from the other three functions. This was done by asking the Ss to verbalize their report of the next stimulus only when signaled to do so. The signal was the $E$ saying, "Now." There were four experimental groups according to a 2 by 2 factorial design: (IF delay - post IF delay) by (filled delay - unfilled delay), and a fifth control group.
\end{abstract}

\section{(1) Unfilled IF Delay Group (D).}

The $E$ signaled $S$ to anticipate the coming word at the appearance of a stimulus on the drum. Ss had to respond within 3 sec. A 30-sec interval followed the $S$ 's response before the next word appeared on the drum. The Ss performed the task until reaching a criterion of one complete trial of eight correct anticipations.

\section{(2) Filled IF Delay Group (FD).}

This group is the same as the D group but Ss had to count backwards by threes, as in the Peterson \& Peterson (1959) technique, during the IF delay period.

\section{(3) Unfilled Post-IF Delay Group (PD).}

This group is the same as the D group, but $E$ signaled $S$ to anticipate the coming word $30 \mathrm{sec}$ after the appearance of the IF stimulus on the drum. The IF word followed immediately after S's response.

\section{(4) Filled Post-IF Delay Group (FPD).}

This group is the same as the PD group, but Ss had to count backwards by threes during the post-IF delay.

\section{(5) Nondelay Control Group (ND).}

This is the same as the D group, with no IF delay. The IF f word appeared immediately after the preceding word.

\section{RESULTS}

Table 1 shows the mean number of trials to criterion and mean number of errors per trial for the five groups. A one-way analysis of variance revealed significant differences among these groups in trials to criterion, $\mathrm{F}(4,35)=34.09, \mathrm{p}<.01$, but no significant differences in number of errors per trial. A Newman-Keuls test $(\alpha=.05)$ showed that Ss in the D and PD groups required a significantly smaller number of trials to reach the criterion than the ND and FD groups. The FPD required significantly fewer trials than the ND group.

A two-way analysis of variance on the number of trials to criterion showed a significant difference on the filled-unfilled factor, $F(1,28)=7.54, p<.05$, and on the location of delay (before or after IF) factor, $F(1,28)=$ $5.15, \mathrm{p}<.05$. No significant interaction was found.

\section{DISCUSSION}

As in paired-associate learning (Atkinson, 1969; Jones, 1968), 
Table 1

Mean Trials to Criterion and Mean Errors Per Trial for the Five Experimental Groups

\begin{tabular}{llcc}
\hline \multicolumn{1}{c}{ Group } & Trials* & $\begin{array}{r}\text { Errors/ } \\
\text { Trial }\end{array}$ \\
\hline 1 & Unfilled IF delay group (D) & 3.25 & 3.28 \\
2 & Filled IF delay group (FD) & 5.63 & 3.93 \\
3 & Unfilled post-IF delay group (PD) & 3.00 & 3.64 \\
4 & Filled post-IF delay group (FPD) & 3.50 & 3.49 \\
5 & Nondelay control group (ND) & 6.13 & 3.18 \\
\hline
\end{tabular}

${ }^{*}$ Results of Newman-Keuls test, $\alpha=.05:$ ND $>$ D, PD, FPD $\mathrm{FD}>\mathrm{D}, \mathrm{PD}$

the results show that unfilled delays of IF (D) facilitates learning. Furthermore, both filled and unfilled post-IF delay (FPD and PD) are also facilitative. The lack of differences between the latter two groups rules out a simple rehearsal interpretation (Jones, 1968), as well as a distribution of practice explanation (Underwood, 1961), for these results.

These results can best be interpreted in terms of the dual functioning of short-term storage (STS) and long-term storage (LTS) mechanisms. The similarity between IF-delay and experiments on short-term memory has already been pointed out by Jones \& Bourne (1964).

The extensive evidence (e.g., Spielberger, Bernstein, \& Ratliff, 1966) that awareness of response-IF contingency is critical for learning leads to the assumption that association between items takes place in the STS. Furthermore, if a stimulus is already stored in the LTS, the S must retrieve it in order to associate it with new stimulus (for similar ideas, see Atkinson \& Wickens, 1971). Once they are formed, associations are transferred to the LTS, where they are organized. When a response is called for, it is retrieved from the LTS.

The filled and unfilled delays effect the STS and LTS differentially. Filled IF delay causes forgetting by interfering with rehearsal and analysis in the STS, but not in the LTS. Post-IF delay-filled and unfilled-aids in transfer, organization, and retrieval of information from the LTS.

The difference between the $\mathrm{D}$ and the $\mathrm{FD}$ groups demonstrates the difficulty of creating an association in the STS under the conditions of filled IF delay.

Comparison of the ND group with the delay groups demonstrates the difficulty of simultaneously having to associate the items, transfer them to the LTS, and retrieve the response word at the moment the feedback word appears on the memory drum.

The insignificant differences between the PD and FPD groups demonstrate that counting backwards by threes affects only the STS, and that post-IF delay helps transfer, organization, and retrieval operations.
The tentative model laid out above assumes that the serial list is learned as a chain of S-R bonds between contiguous words. However, an alternative hypothesis suggests that the serial list is learned through associations formed between the words and their positions (Jensen \& Rohwer, 1965). According to this latter hypothesis, unfilled delays (IF delay or post-IF delay) should facilitate the learning of the position-word association, and filled delays should hinder the formation of the association. While this hypothesis predicts the insignificant difference between the ND and FD groups and the significant difference between $\mathrm{D}$ and FD groups, it does not predict the insignificant difference between the PD and FPD groups. It is also difficult to explain the fact that Ss of the ND or FD groups learn the list with more difficulty than do those of the FPD group, utilizing this hypothesis.

\section{REFERENCES}

Atkinson, R. C. Information delay in human learning. Journal of Verbal Learning \& Verbal Behavior, 1969, 8, 507-511.

Atkinson, R. C., \& Wickens, T. D. Human memory and the concept of reinforcement. In $\mathbf{R}$. Glaser (Ed.), The nature of reinforcement. New York: Academic Press, 1971. Chap. 4.

Balgur, $\mathrm{R}$. The basic word list for elementary schools. Ramat-Gan, Israel: Otsar Hamoreh, 1968.

Bourne, L. E., Jr., \& Bunderson, C. V. Effects of delay of informative feedback and length of post feedback interval on concept identification. Journal of Experimental Psychology, $1963,65,1-5$

Buchwald, A. M. Effects of immediate vs. delayed outcomes in associative learning. Journal of Verbal Learning \& Verbal Behavior, 1967, 6, 317-320.

Jones, R. E. Effects of delay of informative feedback, postfeedback interval, and feedback presentation mode on verbal paired associates learning. Journal of Experimental Psychology, 1968, 77, 87-93.

Jones, R. E., Jr., \& Bourne, L. E., Jr. Delay of informative feedback in verbal learning. Canadian Journal of Psychology, $1964,18,266-280$.

Jensen, A. R., \& Rohwer, W. D., Jr. What is learned in serial learning? Journal of Verbal Learning \& Verbal Behavior, $1965,4,62-75$.

Kintsch, W., \& McCoy, D. F. Delay of information feedback in paired-associate learning. Journal of Experimental Psychology, $1964,68,372-375$.

Peterson, L. R., \& Peterson, M. J. Short-term retention of individual verbal items. Journal of Experimental Psychology, $1959,58,193-198$

Saltzman, I. J. Delay of reward and human verbal learning. Journal of Experimental Psychology, 1951, 41, 437-439.

Spielberger, C. D., Bernstein, I. H., \& Ratliff, R. G. Information and incentive value of the reinforcing stimulus in verbal conditioning. Journal of Experimental Psychology, 1966, 71, 26-31.

Underwood, B. J. Ten years of massed practice on distributed practice. Psychological Review, 1961, 68, 219-247.

(Received for publication May 23, 1973.) 